\title{
RESEARCH REGARDING CALCULATION OF THE TENSILE FORCES OF POLYURETHANE FILM AND PROTECTIVE PAPER, IN THE PROCESS OF POLYURETHANE - PAD - PROTECTIVE PAPER.
}

\author{
Gheorghe Vasile ${ }^{1}$, Alexis Negrea ${ }^{2}$ \\ 1,2,Valahia” University, Romania, gigi.vasile@velfina.com,alexis.negrea@yahoo.com
}

\begin{abstract}
In this paper it is analyzed in terms of kinematics and mechanical, stress occurring in protective paper all the way. It will be analyzed forces and tensions that arise in paper strip in the stretch area, stretching determining race. It follows determination of a continuous tension in the paper strip to optimize the operation
\end{abstract}

Keywords: paper route, tension, polyurethane ***

\section{POSITIONING AND KINEMATICS OF} PROTECTIVE PAPER ROUTE.

As it shows figure 1.the protective paper and polyurethane film ahs different routes. The protective paper has the blue color route and polyurethane film red color route. Both are wrapped in rolls, rolls that will be unrolled by operating with gear motors groups. Both routes follow a predetermined route, routes set by positioning of fixed rollers to engine rollers where they unite and final product will be cut.

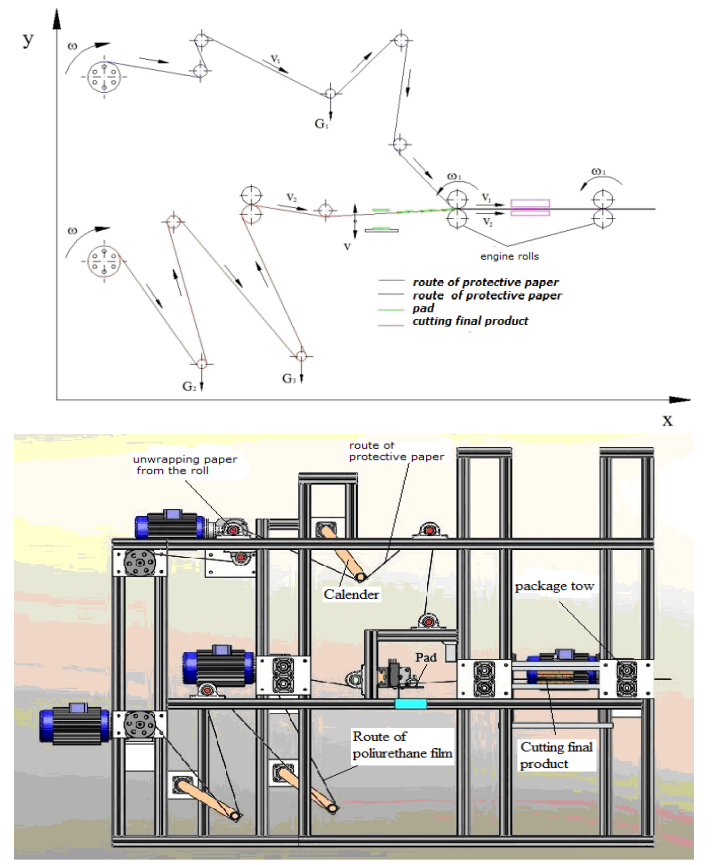

Figure1. Position of rolls for the two routes
The route of protective paper (figure 2) is determined by the impose by conditions for achieving the final product that means package of polyurethane - pad - protective paper. This package has different dimensions in terms of length and width of the package. Therefore for packages smaller than the width of the paper this is cut to the direction of transport, the rest of paper is recovered by wrapping on a roll. The cut is made on

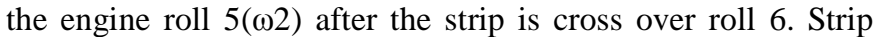
stretch is made between rollers 5 and 2 by a roller mounted on a swing arm (calender). Roll 1 leads the band in the motor area of the package, package is taken by the group of pressing rolls, lead into the cutting die and towed by engine rolls $(\omega 1)$

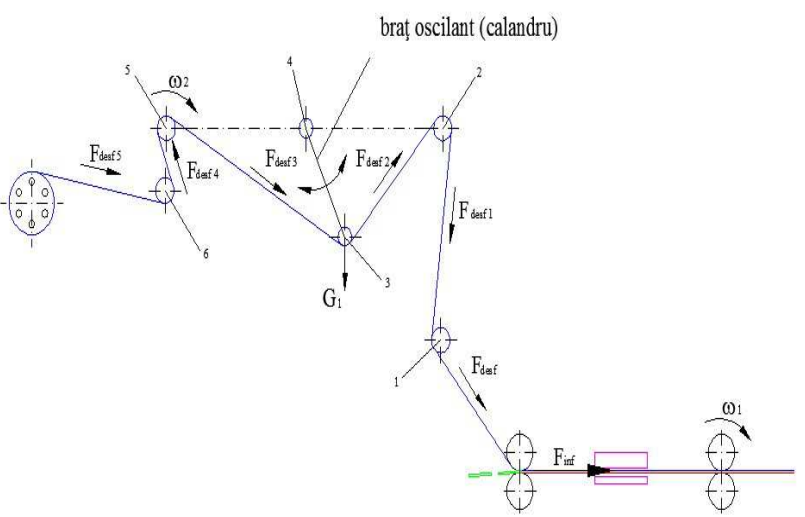

Figure2. Protective paper route Position of stretch roll

Operation from two points of protective paper strip is required by cutting step (cutting) because the package must stop during cutting; during this the strip stays free without tense. For maintain the tension in the strip this is made with gravitational system roll - swing arm. Command of engine roll $5(\omega 2)$ is 
made by superior positioning of stretch roll (figure 3). Also for stopping of it is command by inferior position of this roll.

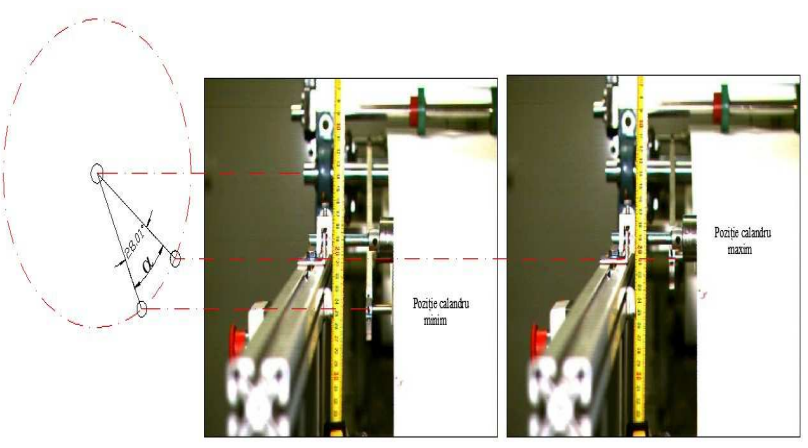

Figure 3 Positioning of the stretch roll. Route made

To maintain a constant tension in paper tape we must analyze the forces from strip, in right of stretching roll, for different positions from minimum to maximum of it.

\section{FORCES FROM PROTECTIVE PAPER}

\section{BAND AT STRETCHING ROLL}

Position of minim for route of stretching roll was established consecutive from construction of equipment (figure 4). The stretching roll makes an angle with the vertical:

$$
\alpha 0=280
$$

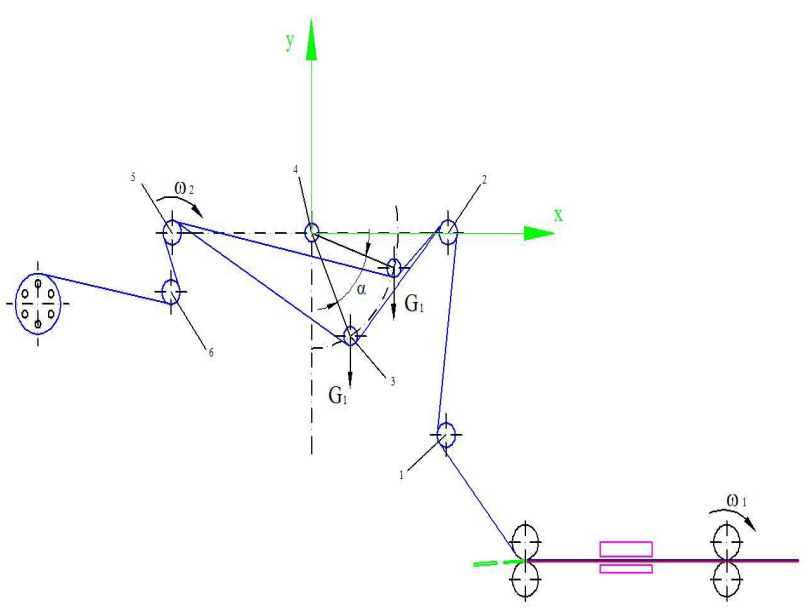

Figure4. Route made.

In point of maxim, roll is at angle $\alpha$, this angle is measure on a image capture that is a frame from a film made with a high speed camera. Angle $\alpha$ measure in this conditions has about the same value with angle $\alpha 0$ :

$$
\alpha \approx 280
$$

Graphic representation of stretching roll position in point of minimum of and forces from the strip for this position are showed in figure 5 .

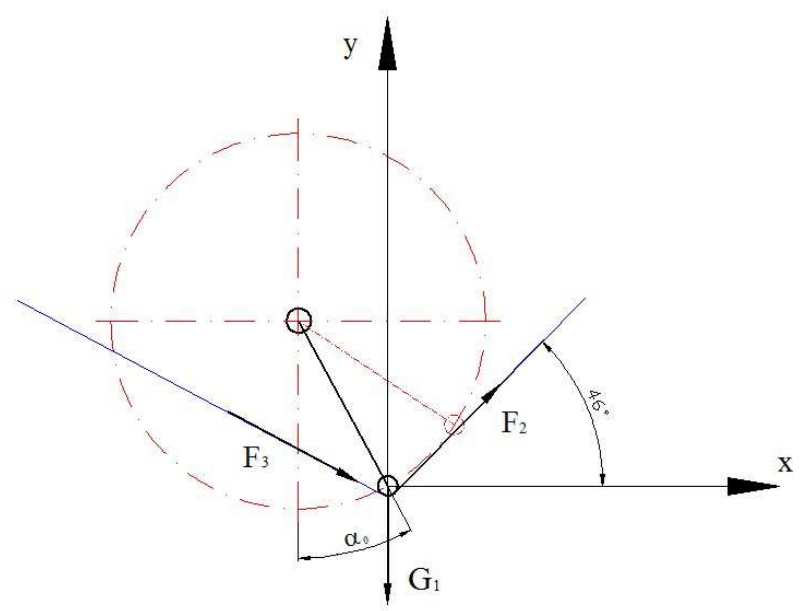

Figure5. Minim position of roll

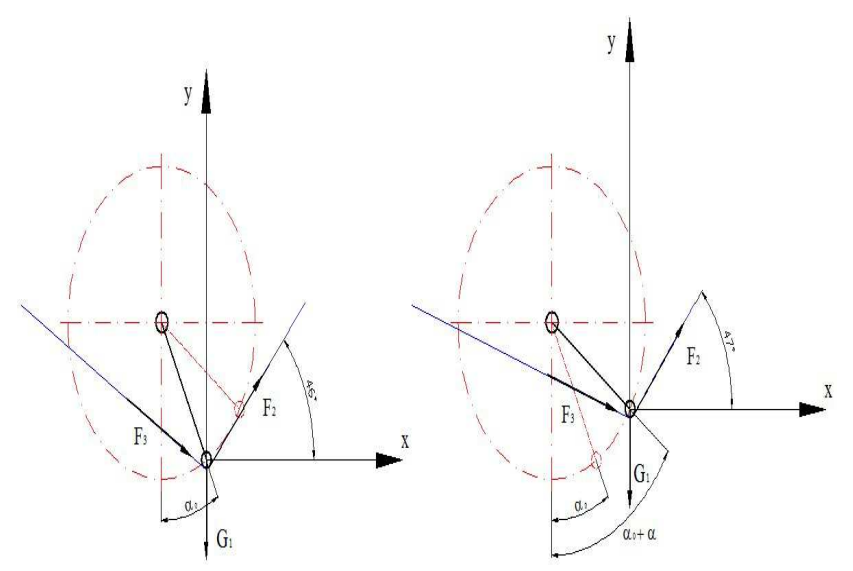

Figure6. Minim and maxim position of roll.

Engines roll strip transmit traction force necessary using friction between roll and strip (figure 7). Wrap angle of the strip on the roll is $\beta[\mathrm{rad}]$ and the coefficient of friction between paper strip and roll $\mu$. The Euler relation can be written:

$$
\text { Fînf }=\text { Fdesf } \cdot e \mu \alpha
$$

Where:

Fînf - force from strip branch which is wrapped roll [N]; Fdesf - force from strip branch which is unwrapped roll [N]; $\beta$ - angle for wrapping of strip on the roll [rad] e - Natural logarithm base . 


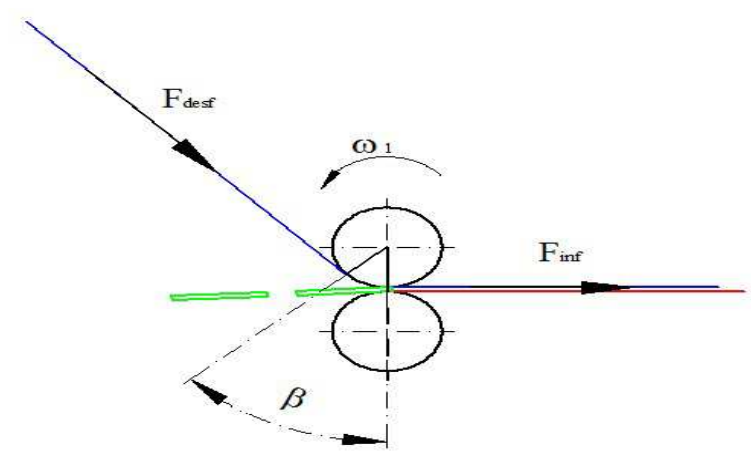

Figure7. Group of rolls for pressing of package

Relation (3) is a maxim of wrapping force for a specific angle and a specific friction coefficient; but in practice the strip can slip from the roll so should be taken a safety coefficient $\mathrm{k}=$ $1,20 . \mathrm{k}$

$$
\text { Fînf }=\text { Fdesf } \cdot e \mu \alpha
$$

In case of stretching roll relation (3) becomes:

$$
\mathrm{F} 2=\mathrm{F} 3 \cdot \mathrm{e} \mu \alpha
$$

Maintaining a constant problem in strip is the end position paper roll tension when engine roll $(\omega 1)$ is stopped for puncher to cut package.

The problem to maintain a constant tension in the paper strip is at the end of stretching roll route, when engine roll $(\omega 1)$ is stopped so that the cutting die to cut the package. We will analyze the extreme position of stretching roll:

$\alpha 0=00-$ stretching roll is in the lower position and then: $\mathrm{G} 1=$ 0 , the gravity force of roll is taking by the joint bearings;

Resultant forces from paper strip, when is trailed:

$\mathrm{R}=\mathrm{F} 2 \sin \gamma-\mathrm{G} 1=\mathrm{F} 2 \sin \gamma$

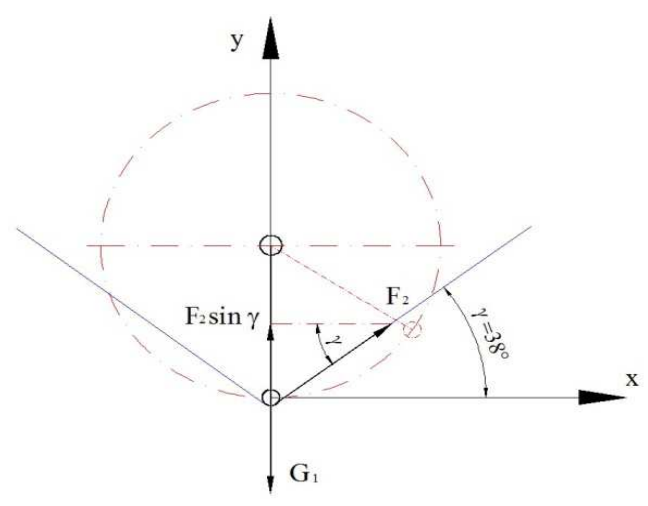

Figure8.
During cutting the strip is stopped. Then: $F 2=0$.

$\mathrm{R}=0$

The strip stays without tension and this must be avoided.

$\alpha 0 \approx 900$ - the stretching roll is the higher position and then:

$\mathrm{G} 1 \neq 0$ - gravity force of roll is made by the mass of the system roll - swing arm;

Resultant of forces from paper strip, when is trailed:

$$
\mathrm{R}=\mathrm{F} 2 \sin \gamma-\mathrm{G} 1
$$

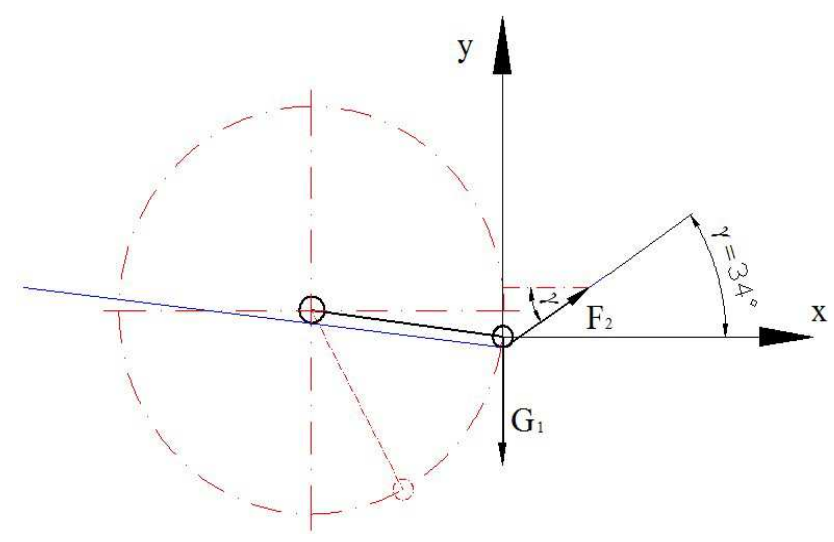

Figure 9

But in this position the strip touch the joint arm, thing unwanted.

It can be seen in figure 4, 6, 8 and 9 that angle $\gamma$ that the strip makes with vertical, between the stretching roll 3 and fix roll 2 takes values between: $\gamma=380 \div 480$, values difference not affects the resultant forces $\mathrm{R}$.

\section{CONCLUSIONS}

In figure 6 can be seen the chosen position for end route sensors installation for stretching roll: $\gamma=460$ - point $\mathrm{t}$ for minim; $\gamma=470$ - point for maxim; chosen position mainly because the angle $\gamma$ varies only with 10 that leads to keep an almost equable tension in paper strip.

\section{REFERENCES}

[1] Viviana Filip, Cornel Marin, Lucian Gruionu, Alexis Negrea - Design, modeling, simulation of mechanical systems, using solid-works, cosmos-motion şi cosmosworks, Publishing Valahia University Press Târgovişte, 2008

[2] Cornel Marin - Strength of materials and components elasticity theory - Publishing Bibliotheca, Târgovişte 2006. 
[3] Cornel Marin- Applications of the elasticity theory in engineering - Publishing Bibliotheca, Târgovişte 2007.

[4] Cornel Marin, Viviana Filip - Modern and classical mechanics - Publishing Valahia University Press Târgoviște. 